\title{
Perfil de propriedades rurais com pastos invadidos por Pteridium arachnoideum na região norte de Mato Grosso e prevalência de hematúria enzoótica bovina ${ }^{1}$
}

\begin{abstract}
Fernando Henrique Furlan²*, Flávio Lisboa da Costa ${ }^{3}$, Silvio C.S. Torres Jr , Flávio Luíz Kerber $^{4}$, Everson dos Santos Damasceno ${ }^{4}$, Alexandre Salino ${ }^{5}$ e Franklin Riet-Correa ${ }^{6}$

ABSTRACT.- Furlan F.H., Costa F.L., Torres Jr S.C.S., Kerber F.L., Damasceno E.S., Salino A. \& Riet-Correa F. 2014. [Profile of farms with pastures invaded by Pteridium arachnoideum in northern Mato Grosso and prevalence of bovine enzootic hematuria.] Perfil de propriedades rurais com pastos invadidos por Pteridium arachnoideum na região norte de Mato Grosso e prevalência de hematúria enzoótica bovina. Pesquisa Veterinária Brasileira 34(8):753-759, Hospital Veterinário, Laboratório de Patologia Animal, Instituto de Ciências da Saúde, Centro Universitário de Sinop, Universidade Federal de Mato Grosso, Av. Alexandre Ferronato 1200, Distrito Industrial, Sinop, MT 78550-000, Brazil. E-mail: furlan@ufmt.br

The profile of 40 farms with pastures invaded by Pteridium arachnoideum in northern Mato Grosso as well as the prevalence of bovine enzootic haematuria (BEH) in dairy and beef cattle in the region are described. The BEH was observed in 15/40 properties with prevalence rates ranging from 0.8 to $16.6 \%$. Aspects related to the deployment of pastures and management are discussed. In most farms where BEH occurs, the pastures were highly invaded by the plant, whereas in most farms where HEB does not occur the pastures had less than $10 \%$ of Pteridium arachnoideum. Deforestation and the use of fire were determinant factors in the invasion of the paddocks by P. arachnoideum.
\end{abstract}

INDEX TERMS: Poisonous plants, bracken fern, Pteridium arachnoideum, Dennstaedtiaceae, plant poisoning, bladder neoplasms, cattle.

RESUMO.- Descreve-se o perfil de 40 propriedades rurais com pastagens invadidas por Pteridium arachnoideum na região norte de Mato Grosso, bem como a prevalência de hematúria enzoótica bovina (HEB) em bovinos de leite e corte nessa região. A HEB foi observada em 15/40 proprie-

\footnotetext{
${ }^{1}$ Recebido em 20 de junho de 2014.

Aceito para publicação em 18 de julho de 2014

${ }^{2}$ Docente do Instituto de Ciências da Saúde, Centro Universitário de Sinop, Universidade Federal de Mato Grosso (UFMT), Av. Alexandre Ferronato 1200, Distrito Industrial, Sinop, MT 78550-000, Brasil. *Autor para correspondência: furlan@ufmt.br

${ }^{3}$ Médico Veterinário, Secretaria de Agricultura, Prefeitura Municipal de Sinop, Av. Tarumãs 1069, Centro, Sinop, MT 78556056. E-mail: flalisboa@ ibest.com.br

${ }^{4}$ Acadêmicos de Medicina Veterinária, UFMT, Centro Universitário, Sinop, MT 78550-000. E-mails: silviojr_vet@hotmail.com, flavio_kerber@ hotmail.com, damasceno.es@gmail.com

${ }^{5}$ Docente do Departamento de Botânica, Instituto de Ciências Biológicas, Universidade Federal de Minas Gerais (UFMG), Cx. Postal 486, Belo Horizonte, MG 30123-970, Brasil. E-mail: salino@icb.ufmg.br

${ }^{6}$ Docente do Centro de Saúde e Tecnologia Rural, Universidade Federal de Campina Grande (UFCG), Av. Universitária s/n, Santa Cecília, Cx. Postal 64, Patos, PB 58708-110, Brasil. E-mail: franklin.riet@pq.cnpq.br
}

dades com prevalências variando entre 0,8 e 16,6\%. Aspectos relacionados à implantação das pastagens e manejos utilizados foram discutidos. A maior parte das propriedades que apresentaram HEB possuíam pastagens altamente invadidas pela planta, enquanto que a maioria das propriedades que nunca apresentaram animais acometidos por HEB possuíam pastos com áreas invadidas abaixo de $10 \%$. 0 desmatamento e a utilização de queimada foram fatores determinantes na invasão de piquetes por P. arachnoidem.

TERMOS DE INDEXAÇÃO: Plantas tóxicas, samambaia, Pteridium arachnoideum, Dennstaedtiaceae, intoxicação por plantas, neoplasia de bexiga.

\section{INTRODUÇÃo}

A intoxicação por Pteridium spp. (Dennstaedtiaceae) é uma importante causa de morte de bovinos no Brasil (Tokarnia et al. 2012). Embora a intoxicação por esta planta seja relativamente comum em muitas regiões do Brasil, na região Centro Oeste, seu diagnóstico é bastante recente (Furlan et al. 2014).

A intoxicação por samambaia se manifesta sob três for- 
mas distintas. Duas crônicas, uma caracterizada por neoplasias no trato digestivo e outra por lesões na bexiga; esta última denominada hematúria enzoótica bovina (HEB) (Döbereiner et al. 1967, Tokarnia et al. 1969, Souto et al. $2006 a, b)$. Há ainda a forma aguda que é associada à síndrome hemorrágica (Marçal et al. 2002, Anjos et al. 2008, 2009).

A HEB é caracterizada pelo desenvolvimento de alterações vesicais de origem neoplásica como hemangiossarcoma, carcinoma in situ, carcinoma de células escamosas, carcinoma de células de transição, papiloma e/ou ainda alterações não neoplásicas relacionadas principalmente ao epitélio de transição como hiperplasia, displasia, cistite cística, metaplasia glandular, proliferação vascular dentre outras (Peixoto et al. 2003, Gabriel et al. 2009).

No Brasil, em locais onde Pteridium arachnoideum é abundante, a HEB tem sido responsável por perdas econômicas significativas (Silva et al. 2009, Galvão et al. 2012). Por outro lado, na região Centro Oeste, não existem dados sobre a ocorrência de hematúria enzoótica bovina, embora existam indícios que esta doença ocorra em algumas propriedades no norte de Mato Grosso (Furlan et al. 2014). Adicionalmente, não se conhecem os fatores envolvidos com a invasão das pastagens por samambaia nessa região. Desse modo, o objetivo deste trabalho foi verificar o perfil das propriedades rurais que possuem pastos invadidos por samambaia e se dedicam à pecuária na região norte de Mato Grosso, bem como levantar a prevalência de hematúria enzoótica bovina nessas propriedades.

\section{MATERIAL E MÉTODOS}

Para este estudo foram selecionadas propriedades rurais que se dedicavam à bovinocultura de corte ou leite e que possuíam piquetes invadidos por Pteridium spp. Foram avaliadas 14 propriedades no município de União do Sul, seis propriedades no município de Nova Bandeirantes e 20 propriedades no município de Sinop, totalizando 40 propriedades.

Durante a visita às propriedades, partes aéreas de Pteridium spp. de 15 propriedades (Propriedades 1 a 15) em que havia histórico de HEB (três em União do Sul e 12 em Sinop), foram amostradas e acondicionadas em exsicata, que foram enviadas para classificação taxonômica aos cuidados do Prof. Dr. Alexandre Salino, curador do Herbário do Departamento de Botânica da Universidade Federal de Minas Gerais. Coletou-se um total de amostras de 45 plantas (três plantas por propriedades). Em seis dessas propriedades havia, durante a visita, um total de 13 bovinos com urina avermelhada que foram avaliados clinicamente. Um bovino que morreu durante uma das visitas à propriedade 3 foi necropsiado e fragmentos de tecidos foram coletados em formalina a $10 \%$ para exame histológico. As amostras foram processadas rotineiramente para confecção de laminas histológicas, coradas com hematoxilina e eosina e observadas em microscópio ótico. Para classificação do índice de invasão por samambaia nas pastagens, foi considerado invasão baixa para índices inferiores a $10 \%$ da área invadida por samambaia; acima disso a invasão foi considerada alta.

Adicionalmente, foi aplicado um questionário adaptado de Galvão et al. (2012) para levantamento dos aspectos epidemiológicos relacionados à invasão da planta nas pastagens, além de aspectos sobre a intoxicação por Pteridium spp. em bovinos (ANEXO I). Os dados não paramétricos obtidos através do questionário fo- ram analisados no programa BioEstat ${ }^{\circledR}$ versão 5.3 (open software) utilizando-se o teste exato de Fisher.

\section{RESULTADOS}

Aspectos epidemiológicos, clínicos, patológicos e identificação da planta

Dentre as propriedades visitadas a área invadida por Pteridium spp. correspondeu, em média, a 9,6\% $\pm 11,6$ da área total dos piquetes, variando entre 1 e $50 \%$ de invasão (Fig.1).

Históricos de HEB foram verificados em 15 dentre as 40 propriedades visitadas. No momento da visita verificou-se que em seis propriedades havia um total de 13 bovinos afetados por HEB (Quadro 1). Clinicamente verificou-se, sangue na urina, queda na produção de leite entre 50 e $60 \%$, apatia, palidez e morte de um bovino. Os sinais clínicos se agravavam durante o período de produção de leite e amenizavam ou até desapareciam no período em que as vacas estavam secas. No bovino necropsiado na propriedade 3 observou-se palidez de mucosas e órgãos, bexiga repleta de sangue e coágulos, com a mucosa espessada e contendo vários nódulos multifocais de coloração vermelho escuro com tamanhos de 0,5 a $2 \mathrm{~cm}$ e uma área focal de $4 \mathrm{~cm}$ de diâmetro com bordos elevados e área central ulcerada (Fig.2). Histologicamente observou-se, na bexiga, três tipos diferentes de neoplasia; na mucosa haviam áreas caracte-

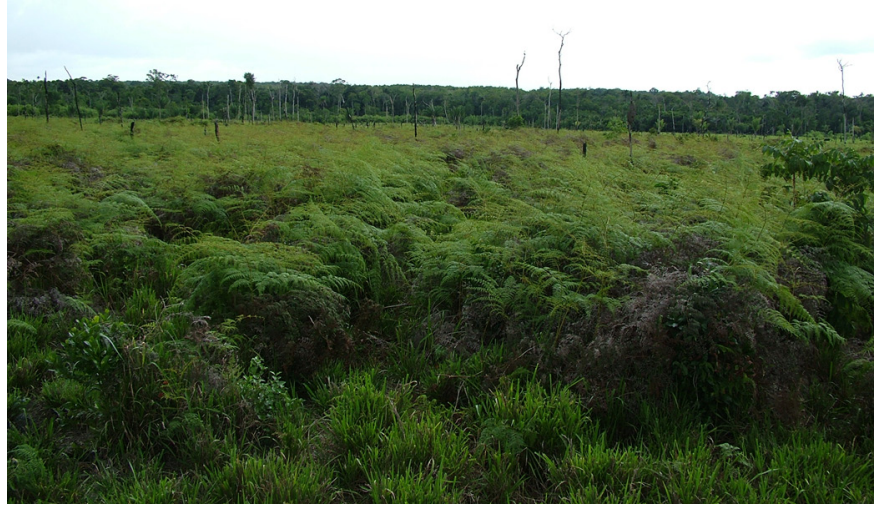

Fig.1. Propriedade 1 no município de Sinop/MT, com pastagem intensamente invadida por Pteridium arachnoideum.

Quadro 1. Dados das propriedades em que foram observados bovinos com HEB durante a visita

\begin{tabular}{cccccc}
\hline $\begin{array}{l}\text { No da pro- } \\
\text { priedade }\end{array}$ & $\begin{array}{c}\text { Muni- } \\
\text { cípio }\end{array}$ & $\begin{array}{c}\text { No de } \\
\text { bovinos }\end{array}$ & $\begin{array}{c}\text { oo de ani- } \\
\text { mais doentes }\end{array}$ & $\begin{array}{c}\text { Prevalência } \\
\text { de HEB (\%) }\end{array}$ & $\begin{array}{c}\text { Invasão dos pique- } \\
\text { tes por Pteridium } \\
\text { arachnoideum }(\%)\end{array}$ \\
\hline 1 & Sinop & 130 & 1 & 0,8 & 40 \\
2 & Sinop & 53 & 1 & 1,9 & 20 \\
$3 *$ & Sinop & 60 & 2 & 3,30 & 30 \\
4 & Sinop & 80 & 2 & 1,2 & 10 \\
5 & Sinop & 18 & 3 & 16,6 & 25 \\
6 & União do & 366 & 4 & 1,1 & 15
\end{tabular}

Sul

* Propriedade em que foi necropsiado um bovino com HEB. 


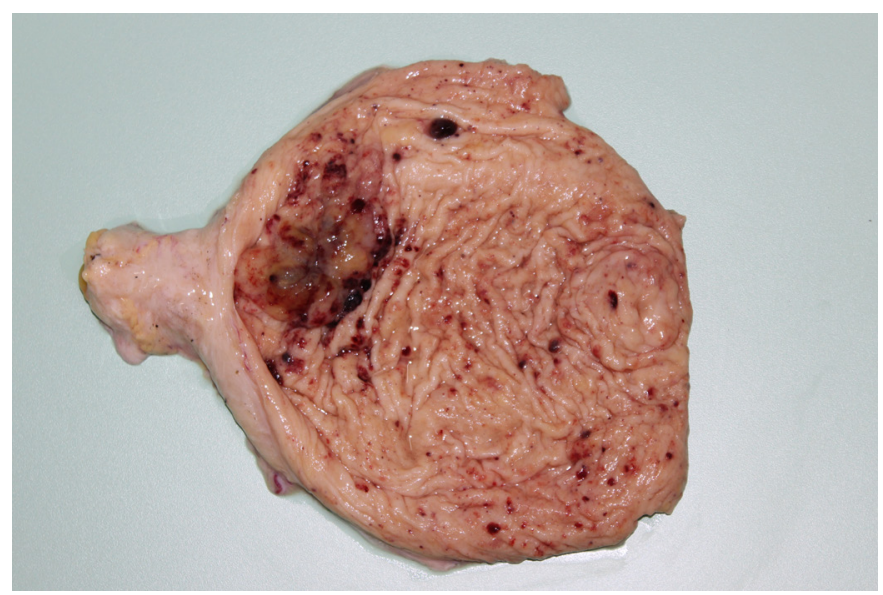

Fig.2. Bexiga de bovino com hematúria enzoótica bovina (HEB), com mucosa espessa e nódulos multifocais de coloração vermelho escuro e uma área focal com bordos elevados e ulcerada.

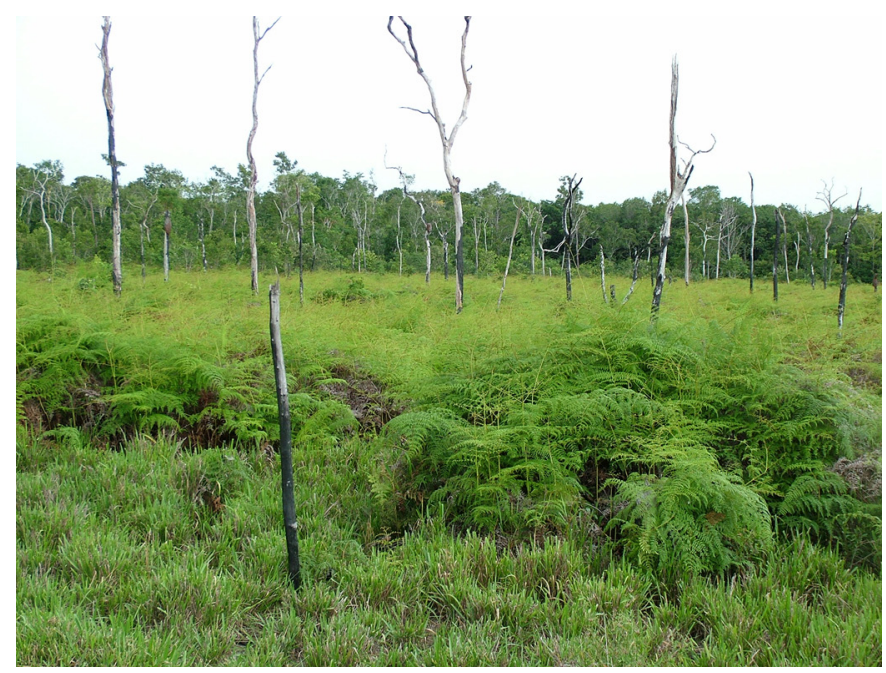

Fig.3. Propriedade 3 no município de Sinop/MT, com piquete intensamente invadido por Pteridium arachnoideum após a realização de queimada. Note que ainda restam na área troncos de árvores com áreas carbonizadas.

rizadas por carcinoma in situ e na mucosa e submucosa haviam hemangiomas e hemangiossarcomas formando nódulos vermelho escuros. Além das neoplasias havia ainda displasia da mucosa e proliferação de tecido mixomatoso na submucosa com áreas multifocais a focalmente extensas de infiltrado linfoplasmocitário de intensidade moderada a acentuada e ainda proliferação moderada e difusa de vasos sanguíneos. Todas as 45 amostras, coletadas dentre as 15 propriedades com históricos de HEB, que foram enviadas para classificação taxonômica foram identificadas como Pteridium arachnoideum.

\section{Perfil das propriedades com pastagens invadidas por Pteridium arachnoideum}

Quando questionados sobre como foi feita a implantação de pastagem na propriedade, cinco proprietários responderam que haviam adquirido suas terras com pastos já formados e 35 realizaram derrubada da floresta nativa, seguida de amontoamento da madeira (enleiramento), quei- mada e plantio do pasto sobre as cinzas. Destes últimos, 32 relataram que já havia a presença de pequena quantidade da planta, na área de floresta, antes da formação das pastagens e três propriedades foram invadidas pela planta apenas depois da implantação de pastagem.

Quando questionados sobre a utilização de fogo nas pastagens, 37 proprietários relataram que já realizaram queimadas nas propriedades, seja apenas durante a implantação das pastagens $(21 / 37)$ ou como manejo frequente para limpeza (16/37). Todos os proprietários observaram que logo após a utilização de queimadas a quantidade de $P$. arachnoideum nos piquetes aumenta (Fig. 3). Dentre eles, 24 afirmaram que isso se deve à ação do fogo, oito acreditam que esse aumento não está relacionado à utilização de queimadas e cinco não souberam responder.

Dentre as 35 propriedades em que foi realizada a implantação de pastagem, em 15 a quantidade de planta nos piquetes, desde sua formação, se manteve igual, em 11 diminuiu, em seis houve aumento e três proprietários não souberam responder. Nas propriedades em que a quantidade de planta se elevou, esse aumento foi atribuído, pelos proprietários, à utilização frequente de queimadas. No que se refere à tentativa de controle da infestação pela planta, 10 produtores já tentaram combate-la com lavração da terra $(3 / 10)$, roçadas $(3 / 10)$, herbicidas $(3 / 10)$ ou associação entre roçada e herbicida $(1 / 10)$ e, dentre esses, cinco afirmaram que obtiveram êxito utilizando roçada $(1 / 5)$, lavração $(2 / 5)$ ou herbicidas $(2 / 5)$. Quando questionados sobre a realização de reforma de pastagem (RP), processo de preparo de solo com lavração, correção, adubação e semeadura do capim, 14 entrevistados realizam tal manejo e destes, 13 afirmaram que a quantidade de samambaia nas pastagens diminuiu após a reforma. Sobre a utilização do sistema de integração lavoura pecuária (ILP), cultivo alternado de lavoura e pastagem numa mesma área com preparo de solo semelhante ao da RP, 11 proprietários faziam uso desta tecnologia e dentre esses, 10 afirmaram que não há ocorrência de samambaia nessas áreas e um relatou que a planta existe apenas nas adjacências à área de ILP. Porém, com o tempo, caso estes manejos não sejam mantidos, $P$. arachnoideum pode voltar gradativamente a invadir essas áreas. Propriedades que utilizavam ILP ou RP possuiam pastagens com índice de invasão menor que as propriedades que não utilizavam estes manejos com $\mathrm{p}<0,01$ e $\mathrm{p}<0,05$, respectivamente (Quadro 2).

Dentre os 40 proprietários questionados, 28 afirmaram que nunca observaram animais ingerindo a planta, 11 achavam que menos de $10 \%$ do total do rebanho consumia e apenas um proprietário afirmou que apenas cavalos comiam. Quando questionados sobre a categoria animal que ingeria samambaia, 28 não sabiam, pois nunca tinham presenciado nenhum animal ingerindo-a, 10 relataram que vacas acima de 48 meses consumiam, um afirmou que observou todas as categorias ingerindo e um observou apenas cavalos consumindo. Entre os 11 proprietários que afirmaram que seus animais ingeriam a planta, cinco achavam que os animais consumiam devido ao vício, cinco afirmaram que era devido à fome e um achava que a o consumo era causado por ambos os fatores. 
Quadro 2. Distribuição do número de propriedades segundo o grau de invasão de piquetes, utilização de RP ou ILP e ocorrência de HEB

\begin{tabular}{|c|c|c|c|c|c|c|c|}
\hline \multirow{2}{*}{$\begin{array}{l}\text { Índice de invasão } \\
\text { de piquetes por } \\
\text { Pteridium } \\
\text { arachnoideum }\end{array}$} & \multicolumn{7}{|c|}{ № de propriedades } \\
\hline & Total & $\begin{array}{c}\text { Que } \\
\text { realizam } \\
\text { RP }\end{array}$ & $\begin{array}{l}\text { Que não } \\
\text { realizam } \\
\text { RP }\end{array}$ & $\begin{array}{c}\text { Que } \\
\text { utilizam } \\
\text { ILP }\end{array}$ & $\begin{array}{c}\text { Que não } \\
\text { utilizam } \\
\text { ILP }\end{array}$ & $\begin{array}{c}\text { Que } \\
\text { apresentaram } \\
\text { animais } \\
\text { com } \mathrm{HEB}^{+}\end{array}$ & $\begin{array}{c}\text { Que nunca } \\
\text { apresentaram } \\
\text { animais } \\
\text { com HEB }\end{array}$ \\
\hline Baixo & 28 & $14^{\mathrm{a} *}$ & 14 & $10^{\text {a** }}$ & 17 & $1^{\mathrm{a} * *}$ & $21^{\mathrm{a} *}$ \\
\hline Alto & 12 & $1^{\mathrm{b} *}$ & 11 & $0^{\mathrm{b} * *}$ & 12 & 5 b** & $4^{\mathrm{b} *}$ \\
\hline
\end{tabular}

$\overline{\mathrm{RP}}=$ Reforma de Pastagens; ILP = Integração Lavoura Pecuária. Letras diferentes na mesma coluna são estatisticamente diferentes $\left({ }^{*} \mathrm{p}<0,05 ;{ }^{* *} \mathrm{P}<0,01\right) .{ }^{+}$Foram levados em consideração apenas animais observados doentes durante a visita.

Já em relação à posse de animais com sintomas de HEB no passado, como a presença de sangue na urina, dentre os 40 proprietários consultados, 25 relataram que nunca possuíram animais que urinassem sangue, ou nunca observaram tal enfermidade, e 15 responderam que em algum momento possuíram animais com tal sintoma. Estes últimos relataram que a categoria animal mais afetada era de bovinos fêmeas, com idade superior a 48 meses. 0 curso clínico da doença foi em média de 7,8 $\pm 6,7$ meses variando entre um e 24 meses em episódios intermitentes. Durante esse período o leite produzido pelos animais doentes era consumido normalmente pelos moradores da propriedade e o excedente era vendido à cooperativas locais. Em 13 propriedades os animais doentes eram descartados ou morriam e nas outras duas esses animais eram negociados e enviados para abate. Seis propriedades apresentaram bovinos clinicamente doentes no momento da visita (13 bovinos doentes de 707 examinados). A prevalência da doença na região foi de 1,8\% $\pm 5,6$ com variações entre $0,8 \%$ e $16,6 \%$ nas propriedades. Quando questionados sobre as possíveis causas da doença, quatro entrevistados responderam que achavam que seria uma infecção do trato urinário, seis não souberam responder e cinco afirmaram que se tratava de intoxicação por samambaia. A ocorrência da doença nas propriedades está relacionada à porcentagem da área dos piquetes invadidos pela planta (Quadro 2).

Com relação ao carcinoma das vias digestivas superiores e à diátese hemorrágica, nenhum dos proprietários tinha conhecimento sobre estas enfermidades.

\section{DISCUSSÃO}

A maioria dos casos de HEB, no Brasil, deve-se ao consumo de Pteridium arachnoideum (Tokarnia et al. 2012), embora exista diagnostico dessa doença atribuída ao consumo de Pteridium caudatum na região norte (Tokarnia 1988). Isso se deve, principalmente, à distribuição dessas espécies no território brasileiro, onde P. arachnoideum ocorre em uma vasta região, enquanto que $P$. caudatum é restrita à região norte e centro oeste (Prado \& Sylvestre 2010, Furlan et al. 2014). Neste estudo, em todas as propriedades onde ocorreram casos de HEB, identificou-se apenas P. arachnoideum, isso se deve ao fato de que esta espécie é encontrada mais frequentemente, neste Estado, que P. caudatum (Furlan et al. 2014).

Todos os proprietários que fizeram a implantação de pastagens em suas terras utilizaram um sistema muito tradicional na região Centro Oeste e Norte que envolve a derrubada da vegetação, queimada, enleiramento e plantio da pastagem por lançamento de sementes, sem lavração. Todos eles observaram que antes da formação da pastagem já havia $P$. arachnoideum nas áreas de floresta nativa, porém em pequena quantidade. Após a realização da derrubada e queimada para implantação das pastagens a planta se alastrou por essas áreas. Muitos produtores utilizam, ainda, a realização de queimadas como um manejo frequente para limpeza dos piquetes já formados e também observaram aumento na quantidade de $P$. arachnoideum; após esse manejo. Como observado neste estudo, muitos autores relatam um incremento na quantidade de Pteridium spp. em áreas que sofreram desmatamento e ação do fogo (Vogl 1964, Martins \& Carvalho 1982, Crane 1990, Gava et al. 2002, Roos et al. 2010, Tobar et al. 2011, Ribeiro et al. 2013). Em regiões fechadas de florestas tropicais a planta não se desenvolve abundantemente devido à falta de luz para seu pleno desenvolvimento, entretanto seu crescimento é favorecido em plena exposição aos raios solares (Alonso-Amelot 1999, Marrs \& Watt 2006, Roos et al. 2010) como ocorre nas áreas recém desmatadas que sofreram ação de fogo observadas neste estudo. Nessas áreas, a proliferação de Pteridium spp. ocorre rapidamente através da germinação de esporos, rebrota e proliferação de seus rizomas, efeito alelopático sobre outras plantas e por sua densa serapilheira. A germinação de esporos de Pteridium spp. é favorecida nessas áreas pois, embora as regiões invadidas por Pteridium spp. possuam solos ácidos (Martins e Carvalho 1982), seus esporófitos jovens se desenvolvem melhor em pH Alcalino, dessa forma, a elevação significativa no $\mathrm{pH}$ do solo que ocorre, por pouco tempo, logo após a queimada, proporciona um ambiente vantajoso para a germinação de Pteridium spp. (Gliessman 1978, Rheiheimer et al. 2003, Tavares Filho et al. 2011). A rebrota e proliferação de rizomas de Pteridium spp. ocorre rapidamente em áreas afetadas pelo fogo. Os rizomas de Pteridium spp. podem ser longos ou curtos; os primeiros formam o eixo principal da planta, crescem rapidamente, não produzem folhas e estão mais profundamente enterrados no solo que os demais. Os rizomas curtos crescem lateralmente aos longos, são produtores de folhas e encontram-se nas porções mais superficiais do solo (Watt 1940). Os rizomas curtos, mais superficiais, são resistentes ao fogo e o calor estimula o crescimento de seus brotos. Em condições normais, a brotação de uma folha inibe a brotação da gema vizinha pela dominância apical, porém após a ação do fogo ocorre a redução na dominância apical e existe uma alta taxa de rebrota. Por outro lado, rizomas longos são menos resistentes ao calor que os curtos, 
porém na profundidade em que se encontram as temperaturas não se elevam o suficiente para mata-los (Roos et al. 2010). Desse modo, o fogo elimina as espécies de plantas concorrentes, o que não ocorre com Pteridium spp., uma vez que, mesmo com a destruição de suas partes aéreas pelo fogo, suas formas adultas sobrevivem à queimada pois possuem rizomas profundamente enterrados no solo, onde a temperatura se eleva pouco, e rizomas superficiais que são resistentes às altas temperaturas (Crane 1990, Roos et al. 2010). Pteridium spp. possui ainda efeito alelopático que inibe a germinação de sementes e modifica a morfologia de algumas plântulas, desfavorecendo o crescimento de plantas concorrentes após a queimada (Silva Matos \& Belinato 2010). As condições descritas acima favorecem a germinação de esporos e a rebrota de Pteridium spp. que se estabelece, em áreas afetadas pelo fogo, com mais vigor que outras plantas. Além disso, o fogo leva à sincronização do ciclo da samambaia. Após o fogo, folhas jovens brotam nos primeiros dias, porém a morte em massa de folhas é observado ao final do primeiro mês, formando a serapilheira. Essa morte não causa repercussão na densidade final da planta pois folhas novas substituem as velhas logo após. A explosão do crescimento após a queimada é visto no $2^{\circ}$ mês e a intensidade da cobertura é dependente da densidade de rizomas que sobrevivem no solo (Roos et al. 2010). A serapilheira formada nos primeiros meses após a queimada impede a passagem de luz para o solo, o que dificulta o crescimento de outras plantas em áreas onde Pteridium spp. se estabeleceu. Além disso, a serapilheira forma uma barreira física que intercepta sementes, impedindo que as mesmas cheguem ao solo. (Vogl 1964, Marrs \& Watt 2006, Silva Matos \& Belinato 2010, Ribeiro et al. 2013).

No que se refere ao controle da invasão das pastagens por $P$. arachnoideum, os resultados obtidos pelos produtores foram bastante variados, com exceção da reforma de pastagem e integração lavoura pecuária, uma vez que propriedades que utilizam estes manejos possuem áreas com menor invasão por samambaia. Segundo Marrs et al (2000) é extremamente difícil erradicar Pteridium spp. em uma área, de fato, pode ser impossível a menos que haja uma completa mudança de uso da terra, por exemplo, para agricultura, entretanto, Le Duc et al (2000) mostraram que a fertilização do solo não reduz a quantidade de Pteridium spp. Portanto, a redução significativa na quantidade de samambaia observada em propriedades que utilizam RP e ILV deve-se provavelmente às práticas agrícolas envolvidas com a preparação da terra utilizadas nesses manejos como: lavração da terra que expões os rizomas ao ressecamento impedindo a rebrota; correção da acidez do solo através da aplicação de calcário, uma vez que a samambaia se desenvolve melhor em solos ácidos; utilização de culturas que diminuem a incidência de luz solar sobre esporófitos de Pteridium sp. ou ainda a associação de todos esses fatores juntos. Como observado neste estudo, outros manejos como roçada, utilização de herbicidas ou lavração do solo podem ser efetivos. Vários autores explicam que para que essas formas de controle sejam efetivas, elas necessitam ser aplicadas em tempo correto e a forma de aplicação varia conforme a época do ano e região estudada (Crane
1990, Marrs \& Watt 2006, Lowday \& Marrs 1983, Le Duc et al. 2000). Isso explica a variabilidade dos resultados obtida pelos produtores consultados neste estudo. Marrs et al. (2000) salientam que uma vez diminuída a quantidade de Pteridium spp. em uma área, para sustentar, a longo prazo, a redução na infestação de samambaia, a aplicação dos tratamentos de controle, na maioria dos casos, deve ser contínua. Essa observação sustenta as experiências vividas a campo pelos proprietários entrevistados que afirmam que, com o tempo, caso estes manejos não sejam mantidos, $P$. arachnoideum pode voltar gradativamente a ser agressiva em áreas onde permaneciam sob controle.

Neste estudo a doença foi verificada em 37,5\% (15/40) das propriedades visitadas. A taxa de invasão dos piquetes foi considerada baixa em 21/25 (84\%) propriedades que nunca apresentaram casos de HEB, por outro lado, no momento da visita, observou-se seis propriedades apresentando animais com HEB e dessas, cinco (83\%) possuíam índice de invasão considerado alto. Desse modo, como observado no Quadro 2, pode-se afirmar que propriedades com incide baixo de invasão de piquetes por $P$. arachnoidum são menos afetadas por HEB que propriedades com incide alto e vice versa.

A prevalência da doença foi baixa na região estudada $(1,8 \%)$, entretanto mostrou-se bastante variável entre as propriedades (0,8-16,6\%). Vários outros estudos tem encontrado prevalência variável de HEB de acordo com a região ou mesmo dentre as propriedades estudadas (Gaste \& Sánches-Villalobos 2008, Tobar et al. 2011, Silva et al. 2009, Galvão et al. 2012, Di Loria et al. 2012, Herencia et al. 2013). Tais números podem estar relacionados a fatores como variação de toxicidade de acordo com a região geográfica ou espécie de Pteridium estudada (Smith et al. 1994, Rasmussen et al. 2008), grau de invasão em cada propriedade ou região além da disponibilidade de alimento para os animais (Gava et al 2002). A classe dos animais afetados pela doença, a sobrevida desses animais (entre um e 24 meses), bem como a apresentação clínica e os aspectos macroscópicos e microscópicos verificados estão em acordo com observações realizadas por outros autores (Peixoto et al. 2003, Gaste \& Sánches-Villalobos 2008, Gabriel et al. 2009, Galvão et al. 2012, Herencia et al. 2013).

Neste estudo verificou-se que alguns produtores ordenhavam bovinos com HEB ou então vendiam esses animais para o abate, de modo que tanto o leite como a carne de bovinos com HEB foram destinados ao consumo humano. Em regiões em que HEB ocorre endemicamente, o leite e a carne de bovinos apresentando sinais da doença são destinados comumente ao consumo humano (Gaste \& Sánches-Villalobos 2008, Galvão et al. 2012). Em um estudo em região endêmica para HEB na região sudeste, Galvão et al (2012) comentam sobre a "venda condicionada" de animais doentes, onde os proprietários só recebem o pagamento pelos animais caso os mesmo cheguem vivos no frigorífico para o abate. Muitos dos princípios tóxicos de plantas são eliminados, por animais doentes, através do leite e o consumo do mesmo pode ser um risco à saúde humana (Riet-Correa e Medeiros 2001). Bovinos que consomem Pteridium spp. apresentam resíduos de ptaquilo- 
sídeo, uma substância cancerígena presente nessa planta (Hirono et al. 1984), no leite e na carne, em quantidades variáveis (Alonso-Amelot et al. 1996, 1998, Fletcher et al. 2011, Calderón et al. 2013). Embora o efeito carcinogênico da ingestão deste cancerígeno por humanos, juntamente com o leite ou carne contaminados, não seja confirmado, alguns autores acreditam que exista uma relação entre a incidência de neoplasias gástricas em humanos e a ingestão de ptaquilosídeo em regiões invadidas por Pteridium spp. (Alonso-Amelot 1997, Alonso-Amelot \& Avendaño 2001, Gomes et al. 2012).

Esse efeito é muito mais preocupante para os produtores que vivem em áreas invadidas por Pteridium spp. e consomem leite ou carne, provenientes de sua própria produção, como observado neste estudo. Apesar desses produtos, muitas vezes, serem destinados a frigoríficos ou laticínios que acabam atendendo à áreas urbanas, a quantidade de ptaquilosídeo é diluída quando a produção das regiões invadidas por Pteridium spp. se junta à produção de áreas livres da planta.

As formas de intoxicação por Pteridium spp. em bovinos são pouco conhecidas entre os produtores entrevistados na região norte de Mato Grosso. No tocante à HEB, 5/15 produtores já possuíram animais com sinais da doença e atribuíram sua causa ao consumo de samambaia. Entretanto, esses mesmos produtores já haviam recebido orientações a respeito dessa doença anteriormente durante o levantamento inicial sobre a importância da doença para a região. A associação, por parte de produtores rurais, entre o consumo de Pteridium spp. por bovinos e a ocorrência de HEB é variável. Enquanto que em algumas regiões essa associação é feita frequentemente (Gaste \& Sánches-Villalobos 2008), em outras, a ocorrência da doença é atribuída principalmente ao consumo de Brachiaria spp. (Galvão et al 2012).

\section{CONCLUSÕES}

Conclui-se que a HEB ocorre na região norte de Mato Grosso, principalmente em propriedades que realizam queimadas, não utilizam reforma de pastagens ou integração lavoura pecuária e, dessa forma, possuem pastos com alta infestação por Pteridium arachnoideum.

A falta de conhecimento sobre as formas de intoxicação por samambaia dificulta a conscientização dos proprietários sobre a importância da doença na região.

Agradecimentos.- Este trabalho foi financiado pelo Instituto Nacional de Ciência e Tecnologia (INCT) Para o estudo do Controle das Intoxicações por Plantas e pela Fundação de Amparo à Pesquisa do Estado de Mato Grosso processo no $177848 / 12$.

\section{REFERÊNCIAS}

Alonso-Amelot M.E, Castillo U., Smith B.L. \& Lauren D.R. 1996. Bracken ptaquiloside in milk. Nature. 382:587.

Alonso-Amelot M.E. 1997. The link between bracken fern and stomach cancer. Milk Nutrition 13(7/8):694-696.

Alonso-Amelot M.E, Castillo U., Smith B.L. \& Lauren D.R. 1998. Excretion, through milk, of ptaquiloside in bracken-fed cows: a quantitative assessment. Lait 78:413423.

Alonso-Amelot M.E. 1999. Helecho macho, salud animal y salud humana. Revta Fac. Agron., La Plata, 16:528-541.
Alonso-Amelot M.E. \& Avendaño M. 2001. Possible association between gastric cancer and bracken fern in Venezuela: An epidemiologic study. Int. J. Cancer 91(2):252-259.

Anjos B.L., Irigoyen L.F., Fighera R.A., Gomes A.D., Kommers G.D. \& Barros C.S.L. 2008. Intoxicação aguda por samambaia (Pteridium aquilinum) em bovinos na região central do Rio Grande do Sul. Pesq. Vet. Bras. 28:501-507.

Anjos B.L., Irigoyen L.F., Piazer J.V., Brum J.S., Fighera R.A. \& Barros C.S.L. 2009. Intoxicação experimental aguda por samambaia (Pteridium aquilinum) em bovinos. Pesq. Vet. Bras. 29:753-766.

Calderón A., Mancebo B., Sánchez L.M., Chiriboga X., Lucero D. \& Marrero E. 2013. Niveles de ptaquilósido en muestras de leche bovina en granjas de San Miguel de Bolívar, provincia Bolívar, Ecuador. Revta Salud Anim. 35(2):109-115.

Crane M.F. 1990. Pteridium aquilinum. U.S. Department of Agriculture, Forest Service, Rocky Mountain Research Station, Fire Sciences Laboratory, Fire Effects Information System, Disponível em <http://www.fs.fed.us/ database/feis/plants/fern/pteaqu/all.html acessado em 07/2013>

Di Loria A., Piantedosi D., Cortese L., Roperto S., Urraro C., Paciello O., Guccione J., Britti D. \& Ciaramella P. 2012. Clotting profile in cattle showing chronic enzootic haematuria $(\mathrm{CEH})$ and bladder neoplasms. Res. Vet. Sci. 93:331-335.

Döbereiner J., Tokarnia C.H. \& Canella C.F.C. 1967. Ocorrência de hematúria enzoótica e de carcinomas epidermóides no trato digestivo superior em bovinos no Brasil. Pesq. Agropec. Bras. 2:489-504.

Fletcher M.T., Reichmann K.G., Brock I.J., McKenzie R.A. \& Blaney B. 2011. Residue potential of norsesquiterpene glycosides in tissues of cattle fed austral bracken (Pteridium esculentum). J. Agric. Food Chem. 59:85188523.

Furlan F.H., Mendes E.R.S., Ducatti K.R., Marcon G.C. Dombroski T., Amorim T.M. \& Riet-Correa F. 2014. Intoxicação aguda por Pteridium arachnoideum e Pteridium caudatum em bovinos e distribuição da planta em Mato Grosso. Pesq. Vet. Bras. 34. (Em publicação)

Gabriel A.L., Kommers G.D., Masuda E.K., Fighera R.A., Piazer J.V.M., Barros C.S.L., Martins T.B. \& Rosa F.B. 2009. Aspectos clínico-hematológicos e lesões vesicais na intoxicação crônica espontânea por Pteridium aquilinum em bovinos. Pesq. Vet. Bras. 29(7):515-525.

Galvão A., Brito M.F., Aragão A.P., Yamasaki E.M., Peixoto P.V. \& Tokarnia C.H. 2012. Sobrevivência/viabilidade de bovinos com hematúria enzoótica após transferência para região livre de Pteridium arachnoideum. Pesq. Vet. Bras. 32(9):887-902.

Gaste L. \& Sánchez-Villalobos A. 2008. Conductas y creencias de los productores rurales de los municipios Sapopema y Sâo Jerónimo da Serra, estado de Paraná, Brasil sobre las intoxicaciones crónicas por genotipos del Pteridium. Revta Cient., Maracaibo, 18(4):358-367.

Gava A., Neves D.S., Gava D., Saliba T.M., Schild A.L. \& Riet-Correa F. 2002. Bracken Fern (Pteridium aquilinum) poisoning in cattle in southern Brasil. Vet. Hum. Toxicol. 44(6):362-365.

Gomes J., Magalhães V., Amado I.F., Aranha P., Ovesen R.G., Hansen H.C.B., Gärtner F., Reis C.A. \& Touati E. 2012. Pteridium aquilinum and its ptaquiloside toxin induce DNA damage response in gastric epithelial cells, a link with gastric carcinogenesis. Toxicol. Sci. 126(1):60-71.

Gliessman S.R. 1978. The establishment of bracken following fire in tropical habitats. Am. Fern J. 68(2):41-44.

Herencia B.K., Falcón P.N., García P.M., Chavera C.A. \& Gonzáles E.C. 2013. Prevalencia de hematuria vesical enzoótica bovina determinada mediante urianálisis en Oxapampa, Perú. Revta Investig. Vet. Perú 21(4):50-57.

Hirono I., Aiso S., Yamaji T., Mori H., Yamada K., Niwa H., Ojika M., Wakamatsu K., Kigoshi H., Niiyama K. \& Uosaki Y. 1984. Carcinogenicity in rats of ptaquiloside isolated from bracken. Gann. 75:833-836.

Le Duc M.G., Pakeman R.J., Putwain P.D. \& Marrs R.H. 2000. The variable responses of bracken fronds to control treatments in Great Britain. Ann. Bot. 85(Suppl.B):17-29.

Lowday J.E. \& Marrs R.H. 1983. Some of the effects of cutting bracken (Pteridium aquilinum (L.) Kuhn) at differente times during the summer. J. Environ. Manage. 17:373-380. 
Marçal W.S., Gaste L., Reichert Netto N.C. \& Monteiro F.A. 2002. Intoxicação aguda pela samambaia (Pteridium aquilinum (L.) Kuhn) em bovinos da raça Aberdeen Angus. Arch. Vet. Sci. 7:77-81.

Marrs R.H., Le Duc M.G., Mitchell R.J., Goddard D., Paterson S. \& Pakeman R.J. 2000. The ecology of bracken: its role in succession and implications for control. Ann. Bot. 85(Suppl.B):3-15.

Marrs R.H. \& Watt A.S. 2006. Biological flora of the British Isles: Pteridium aquilinum (L.) Kuhn. J. Ecol. 94:1272-1321.

Martins G. \& Carvalho. 1982. Uma comunidade successional dominada por Pteridium aquilinum (L.) Kuhn no município de Lavras, Estado de Minas Gerais. Planta Daninha 1:35-39.

Prado J. \& Sylvestre L.S. 2010. Samambaias e Licófitas, p.522-569. In: Forzza R.C. (Ed.), Catálogo de Plantas e Fungos do Brasil. Vol.1. Instituto de Pesquisas, Jardim Botânico do Rio de Janeiro, Rio de Janeiro. 875p. Disponível em <http://www.jbrj.gov.br/publica/livros_pdf/plantas_fungos_vol1.pdf>

Peixoto P.V., França T.N., Barros C.S.L. \& Tokarnia C.H. 2003. Histopathological aspects of Bovine Enzootic Hematuria in Brazil. Pesq. Vet. Bras. 23(2):65-81.

Rasmussen L., Lauren D., Smith B. \& Hansen H. 2008. Variation in ptaquiloside content In bracken (Pteridium esculentum (Forst.) Cockayne in New Zealand. N. Z. Vet. J. 56(6):304-309.

Rheinheimer D.S., Santos J.C.P., Fernandes V.B.B., Mafra A.L. \& Almeida J.A. 2003. Modificações nos atributos químicos de solo sob campo nativo submetido à queima. Ciência Rural 33(1):49-55.

Ribeiro S.C., Botelho S.A., Fontes M.A.L., Garcia P.O. \& Almeida H.S. 2013. Regeneração natural em áreas desmatadas e dominadas por Pteridium aquilinum (L.) Kuhn na serra da Mantiqueira. Cerne 19(1):65-76.

Riet-Correa F. \& Medeiros R.M.T. 2001. Intoxicações por plantas em ruminantes no Brasil e no Uruguai: importância econômica, controle e riscos para a saúde pública. Pesq. Vet. Bras. 21(1):38-42.

Roos K., Rollenbeck R., Peters T., Bendix J. \& Beck E. 2010. Growth of tropical bracken (Pteridium arachnoideum): response to weather variations and burning. Inv. Plant Sci. Mgmt. J. 3:402-411.

Silva M.A., Scádua C.M., Dórea M.D., Nunes L.C., Martins I.V.F. \& Donatele D.M. 2009. Prevalência de hematúria enzoótica bovina em rebanhos lei- teiros na microrregião do Caparaó, Sul do Espírito Santo, entre 2007 e 2008. Ciência Rural 39(6):1847-1850.

Silva Matos D.M. \& Belinato T.A. 2010. Interference of Pteridium arachnoideum (Kaulf.) Maxon. (Dennstaedtiaceae) on the estabilishment oh rainforest trees. Bras. J. Biol. 70(2):311-316.

Smith B.L., Seawright A.A., Ng J.C., Hertle A.T., Thomson J.A. \& Bostock P.D. 1994. Concentration of ptaquiloside, a major carcinogen in bracken fern (Pteridium spp.), from eastern Australia and from a cultivated worldwide collection held in Sydney, Australia. Nat. Toxins 2(6):347-353.

Souto M.A.A, Kommers G.D., Barros C.S.L., Piazer J.V.M., Rech R.R., RietCorrea F. \& Schild A.L. 2006a. Neoplasias do trato alimentar de bovinos associadas ao consume espontâneo de samambaia (Pteridium aquilinum). Pesq. Vet. Bras. 26:112-122.

Souto M.A.A, Kommers G.D., Barros C.S.L., Rech R.R. \& Piazer J.V.M. 2006b. Neoplasmas da bexiga associados à hematúria enzoótica bovina. Ciência Rural 36:1647-1650.

Tavares Filho J., Ferreira R.R.M. \& Ferreira V.M. 2011. Fertilidade química de solo sob pastagens formadas com diferentes espécies nativas e com Brachiaria decumbens manejadas com queimadas anuais. Semina, Ciênc. Agrárias 32(Supl.1):1771-1782.

Tobar A.C., Faz E.M., Murilllo V. \& Veja V. 2011. Reporte de casos de hematuria enzoótica bovina por Ingestión de pteridium arachnoideum en la región ganadera de san miguel de bolívar, provincia bolívar, ecuador. Revta Salud Anim. 33(3):197-202.

Tokarnia C.H., Döbereiner J. \& Canella C.F.C. 1969. Ocorrência de hematúria enzoótica e de carcinomas epidermóides no trato digestivo superior em bovinos no Brasil. I. Estudos complementares. Pesq. Agropec. Bras. 4:209-224.

Tokarnia C.H. 1988. Relatório de viagem ao município de Manacapuru, Estado de Amazonas, para estudar doença em bovinos, no período de 25 a 29 de janeiro de 1988. 3p.

Tokarnia C.H., Brito M.F., Barbosa J.D., Peixoto P.V. \& Döbereiner J. 2012. Plantas Tóxicas do Brasil. 2ª ed. Helianthus, Rio de Janeiro. 566p.

Watt A.S. 1940. Contributions to the ecology of bracken (Pteridium aquilinum). I. The Rhizome. New Phytol. 39:401-422.

Vogel R.J. 1964. The effects of fire in the vegetation composition of bracken-grasslands. Trans. Wis. Acad. Sci. Arts Lett. 53:67-82. 